\title{
Identification, Analysis and Suggestions for Accident Blackspots
}

\author{
Kumarraju B.C..$^{*}$, Chandre Gowda C. ${ }^{2}$, Vijay Kumar Y.M. ${ }^{3}$ \& Karthika B.S. ${ }^{4}$ \\ ${ }^{I}$ Dept. of Civil Engineering, Sapthagiri College of Engineering, VTU, Bengaluru, India. Email: kumarraju@sapthagiri.edu.in* \\ ${ }^{2}$ Centre for Incubation, Innovation, Research and Consultancy, Jyothy Institute of Technology, VTU, Bengaluru India. \\ ${ }^{3}$ Department of Civil Engineering, Adichunchanagiri Institute of Technology, Chikmagalur, Karnataka, India. \\ ${ }^{4}$ Department of Civil Engineering, Jawaharlal Nehru National College of Engineering, Shimoga, Karnataka, India.
}

DOI: http://doi.org/10.38177/ajast.2021.5404

Copyright: (๑) 2021 Kumarraju B.C. et al. This is an open access article distributed under the terms of the Creative Commons Attribution License, which permits unrestricted use, distribution, and reproduction in any medium, provided the original author and source are credited.

\section{AB STR ACT}

In the study the four black spots along the state highway-39 was recognized. The current conditions and causes for the accidents were analyzed based on the data procured from first information report. Later these spots were physically examined and the suggestions for possible reduction of the fatalities were provided. Accident density and weighted severity index were determined and potential suggestions to reduce the fatalities are described. The measures are suggested to reduce the accidents. Since, safer roads provide safe journey for all the stake holders.

Keywords: Black spots, Accident, Suggestions, Safe driving.

\section{Introduction}

The drastic growth in the population results to increase the population density. This rise leads to high vehicle volume on the roads. Since the vehicle density is higher for the current road availability which causes conjunction and long period of waiting on the roads.

Totally $11 \%$ of deaths are accident related in the world, across 199 countries [1]. In India about 449,002 accidents occurred in 2019, resulting 1,51,113 turned deaths as per the report [1]. The table 1 shows the percentage of deaths and corresponding road networks in India till 2019. It shows that the national and state highways are the major contributor to the road accidents. Table 2 shows the fatality rate and vehicle density per ten thousand vehicles from 1970 to 2017. From this table it can be noted that the density is increasing at higher rate and due to proper road ways, the accidents have been reduced.

Table 1. Accident details of India, 2019 [1]

\begin{tabular}{|c|c|c|c|c|}
\hline \multirow{2}{*}{ Sl. No. } & \multirow{2}{*}{ Road network (\%) } & \multirow{2}{*}{ Highway } & \multicolumn{2}{|l|}{ Accident contribution (\%) } \\
\cline { 4 - 5 } & & & Deaths & Injured \\
\hline 1 & 2.03 & National & 35.65 & 30.47 \\
\hline 2 & 3.01 & State & 25.46 & 24.78 \\
\hline 3 & 94.96 & Others & 38.89 & 44.75 \\
\hline
\end{tabular}

About $37 \%$ of accident deaths are through two wheeler; and16\% are from cars and other light motor vehicles. Totally 26 places are recognized as black spots in karnataka distributed over nine districts (Mysore, Tumkur, Mangalore, Hubbali-Dharwad, Davanagere, Belgaum, Gulbarga, Bellary and Mandya). In the study four black spots on state highway-39 from 8th mile to Hesaraghatta were recognized and considered for analysis. Many road 


\section{AJAST}

Asian Journal of Applied Science and Technology (AJAST)

Volume 5, Issue 4, Pages 30-38, Oct-Dec 2021

accidents have been reported and National Highway Authority of India has come up with numerous projects which have reduced the black spots up to certain extent [2].

Table 2. Vehicle density and fatality rate (report from GOI, 2021)

\begin{tabular}{|c|c|c|c|}
\hline SI. No. & Year & Fatality rate/10,000 vehicles & Vehicle density/Km \\
\hline 1 & 1970 & 103.5 & 1.18 \\
\hline 2 & 1980 & 53.1 & 3.03 \\
\hline 3 & 1990 & 28.3 & 9.65 \\
\hline 4 & 2000 & 16.2 & 14.73 \\
\hline 5 & 2010 & 10.5 & 27.88 \\
\hline 6 & 2014 & 7.3 & 35.3 \\
\hline 7 & 2017 & 5.8 & 42.95 \\
\hline
\end{tabular}

\section{Study Area and data}

The study area was selected in Bengaluru region through which state highway - 39 passes and for study purpose the $13 \mathrm{~km}$ stretch of road was selected between $8^{\text {th }}$ mile to Hesaraghatta. The area location falls between $13.060 \mathrm{~N}$ $13.130 \mathrm{~N}$ and $77.500 \mathrm{E}-77.480 \mathrm{E}$ (figure 1)

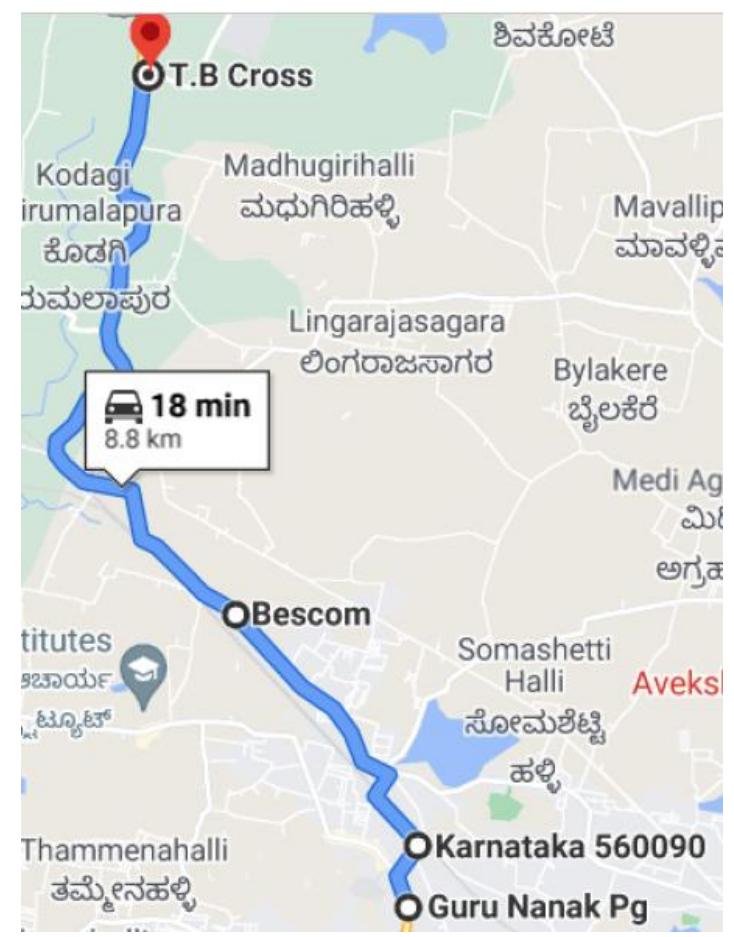

Fig.1. Location of all black spots recognized (Source, google maps)

The accidents record for the five years in this route was plotted in figure 2 and it was noted that the accidents were more between 3:00 pm to 9:00 pm. 


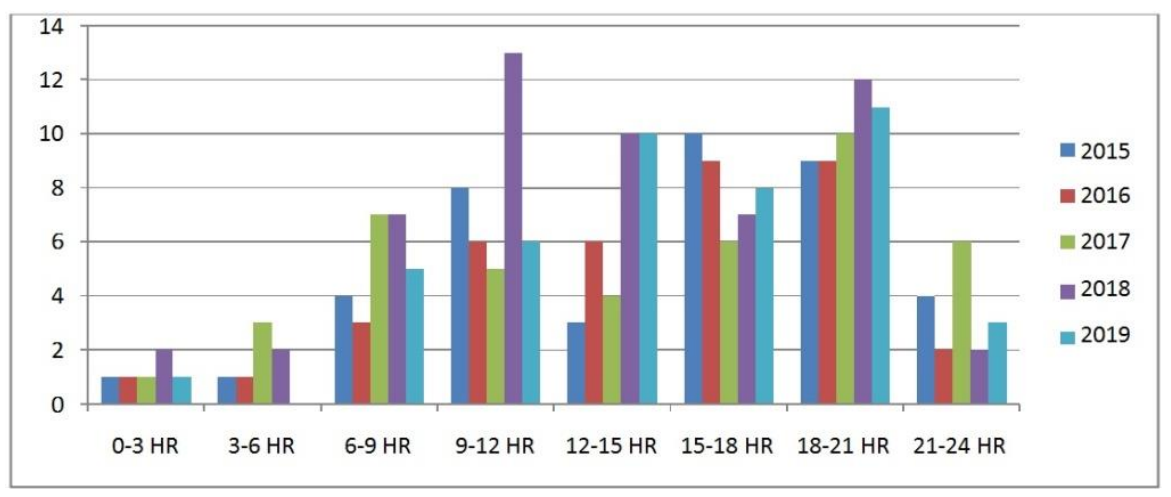

Fig.2. Accident time from year 2015 to 2019

In all these black spots from the last 5 year accident data we can observe that highest number of accident were registered in the year 2018, total number of accidents were 56 and fatal were 9, grievous were 20 and minor were 27. As per the study, most of the fatal accidents were by the motorcycles at these black spots.

\section{Methodology}

Weighted severity index (WSI), Method of ranking (MR), accident density (AD) and statistical analysis (SA) are generally used to identify the black spots [3] in general. In the study WSI and AD are used for the analysis.

\section{Accident Density method}

The density estimation is calculated by event density around each point for measured distance from the point of the event. The unit length considered is 1000 meters. Predetermined numbers of accidents were calculated as average number of accidents that have occurred per unit length.

\section{Weighted Severity Index}

The black spots in WSI are prioritized based on the severity of the location [4] preliminary survey was carried to identify the probable accident prone location on main road of the study area. It is given by,

$\mathrm{WSI}=\left(\mathrm{N}_{\mathrm{f}} \mathrm{W}_{\mathrm{f}}+\mathrm{N}_{\mathrm{s}} \mathrm{W}_{\mathrm{s}}+\mathrm{N}_{\mathrm{m}} \mathrm{W}_{\mathrm{m}}\right)$,

Also represented as,

$\mathrm{WSI}=(41 \mathrm{~K})+(4 \mathrm{GI})+(\mathrm{MI})[2][6]$

Where,

$\mathrm{W}_{\mathrm{f}}=$ weight assigned to fatal accidents, $\mathrm{W}_{\mathrm{s}}=$ weight assigned to grievous accidents,

$\mathrm{W}_{\mathrm{m}}=$ weight assigned to minor accidents, $\mathrm{K}=$ number of total fatal accidents,

$\mathrm{N}_{\mathrm{f}}=$ number of fatal accidents, $\mathrm{GI}=$ number of grievous accidents,

$\mathrm{N}_{\mathrm{f}}=$ number of fatal accidents, $\mathrm{N}_{\mathrm{s}}=$ number of grievous accidents,

$\mathrm{N}_{\mathrm{m}}=$ number of minor accidents, $\mathrm{MI}=$ number of minor accidents

From physical survey and geometrical variation, significant four black spots were recognized for the analysis. 


\section{Observations and Summary}

The 4 spots considered (Bengaluru Karnataka, India) through WSI and accident density method are given below:
i) Sapthagiri junction
ii) Chikkabanavara
iii) Soladevanahalli near bescom office
iv) $\quad$ TB cross near heasaraghatta

The location details of sapthagiri junction have been represented in figure 3 and table 3 .

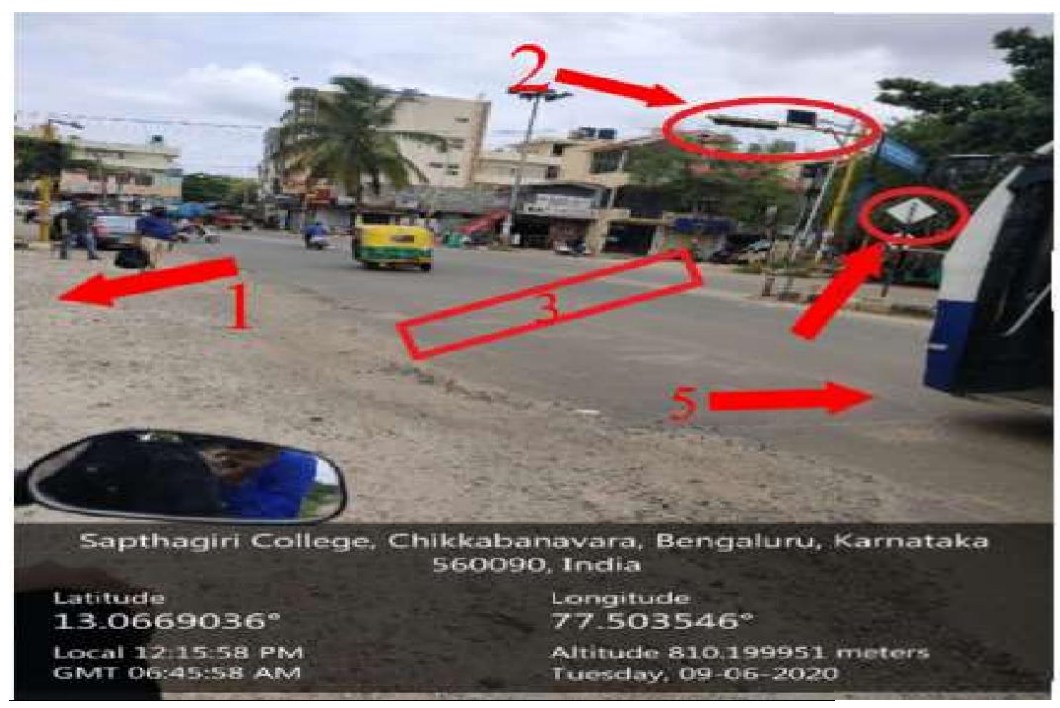

Fig.3. Location of Sapthagiri engineering college junction

From the figure 3, it can be noted that the foot path provided in not appropriate (1) highlighted in red). Then the traffic signal (2) is not function, zebra crossing (3) for pedestrians is missing. Then sign boards (4), speed breaker (5) and other markings are missing.

Table 3. Existing road conditions at Chikkabanavara, India

\begin{tabular}{|c|c|c|c|}
\hline Sl. No. & Categories & Sub-categories & Specific \\
\hline 1 & Police records (FIR) & Accidents & 34 fatal injuries \\
\hline \multirow{2}{*}{2} & Road Conditions (IRC:SP027) & Pavement failure & Completely \\
& & Foot paths & Uneven \\
& Type of Collision & Hack to back & 20 \\
\hline 3 & & Side sweep & 01 \\
\hline 4 & Sign Board & Sign boards and indication & None \\
\hline
\end{tabular}


Volume 5, Issue 4, Pages 30-38, Oct-Dec 2021

\begin{tabular}{|c|c|c|c|}
\hline 5 & Visibility & Day and Night & Good \\
\hline 6 & Bush Clearance & Shreds and other & None \\
\hline 7 & Street Light & Halogen or LED & Exists \\
\hline
\end{tabular}

The reduction in speed may reduce the number of accidents [5]. The suggestions to improve the driving experience are given below:

a) Marking and delineators need to be provided.

b) Mandatory signal and sign board for speed limits

c) Foot path for pedestrians to be provided on both sides

d) The unevenness need to be addressed

e) Standard median to be built upon

The location details of chikkbanavara are given in figure 4 and table 4 .

Table 4. Existing road conditions at Chikkabanavara

\begin{tabular}{|c|c|c|c|}
\hline Sl. No. & Categories & Sub-categories & Specific \\
\hline 1 & Police records (FIR) & Accidents & 29 fatal injuries \\
\hline 2 & Road Conditions (IRC:SP027) & Pavement failure & Partially \\
& & Spoot paths & Nonen breaker \\
\hline 3 & Type of Collision & Back to back & 12 \\
\hline 4 & Sign Board & Side sweep & 02 \\
\hline 5 & Visibility & Day and Night & Fair/Bad \\
\hline 6 & Bush Clearance & Shreds and other & Exists \\
\hline 7 & Street Light & Halogen or LED & Does not exists \\
\hline
\end{tabular}

From figure 4, the issues like sign board, road condition s and others can be observed. So, the suggestions to reduce the accidents are given below:

a) Marking and delineators need to be provided.

b) Mandatory signal and sign board for speed limits.

c) Foot path for pedestrians to be provided. 
d) All the pot holes need to be filled and natural drains to be provided.

e) Street lights to be provided.

f) Standard median to be built upon.

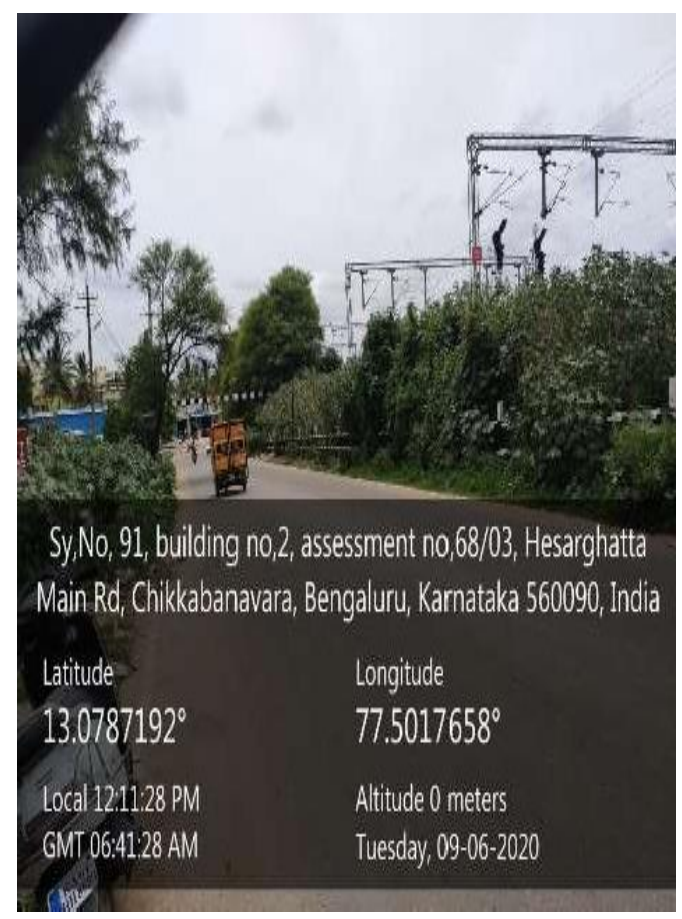

Fig.4. Location of Chikkabanavara

The location details of soladevanahalli near bescom are given in figure 5 and table 5 .

Table 5. Existing road conditions at Soladevanahalli near bescom office

\begin{tabular}{|c|c|c|c|}
\hline Sl. No. & Categories & Sub-categories & Specific \\
\hline 1 & Police records (FIR) & Accidents & 27 fatal injuries \\
\hline 2 & Road Conditions (IRC:SP027) & Pavement failure & less \\
& & Foot paths & Noed breaker \\
& & Head on & 12 \\
3 & Type of Collisiontific & Back to back & 14 \\
\hline 4 & Sign Board & Sign boards and indication & None \\
\hline 5 & Visibility & Day and Night & Good/Fair \\
\hline 6 & Bush Clearance & Shreds and other & Exists \\
\hline 7 & Street Light & Halogen or LED & Does not exists \\
\hline
\end{tabular}



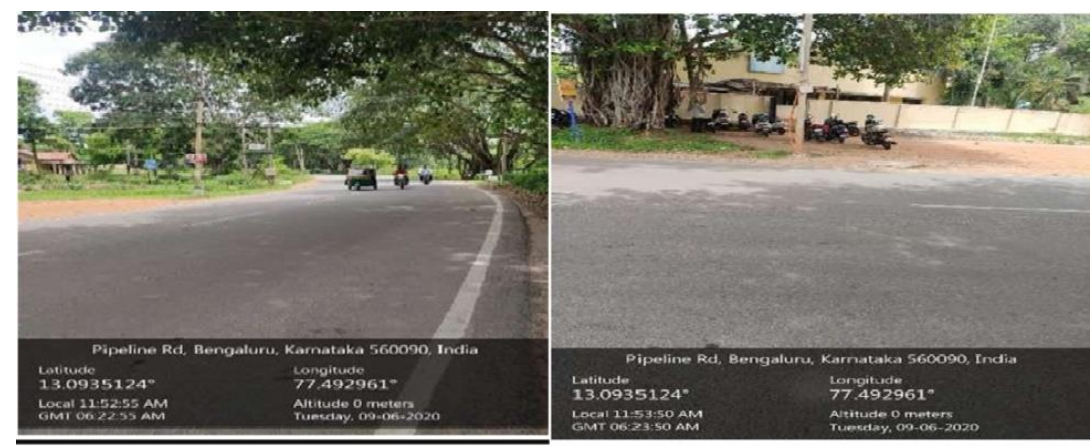

Fig.5. Location of Soladevanahalli near bescom office

The figure 5 and table 5 also represents the similar problems faced as the others can be observed, so the suggestions to reduce these are given below:

a) Marking and delineators need to be provided.

b) Mandatory sign boards of speed limit need to be provided

c) Foot path for pedestrians to be provided.

d) Mild pot holes need to be filled

e) Street lights to be provided.

f) Standard median to be built upon.

The location and details of TB cross near hesaraghatta is given in figure 6 and table 6 .

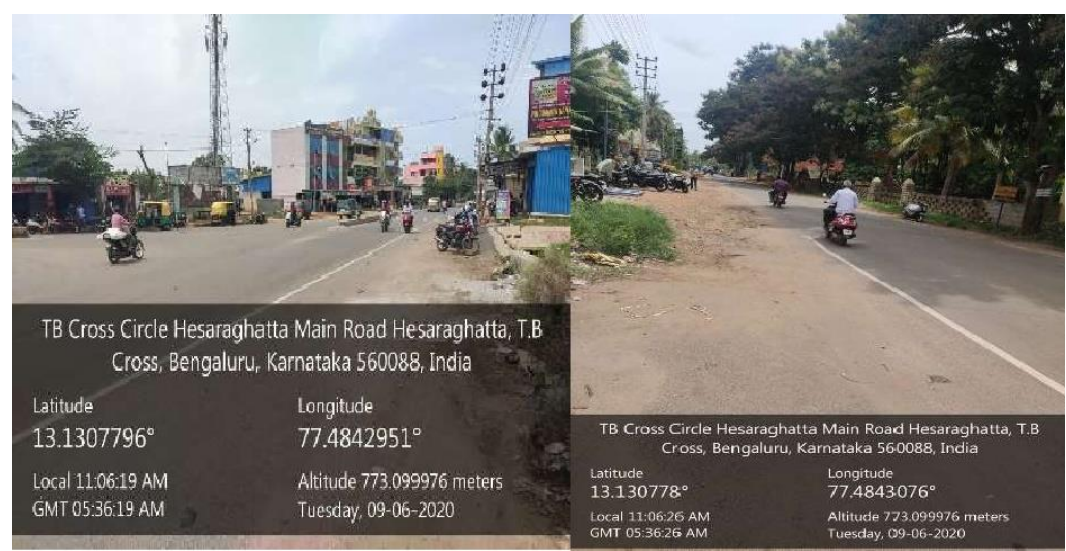

Fig.6. Location of TB cross near heasaraghatta

Table 6. Existing road conditions at TB cross near heasaraghatta

\begin{tabular}{|c|c|c|c|}
\hline Sl. No. & Categories & Sub-categories & Specific \\
\hline 1 & Police records (FIR) & Accidents & 36 fatal injuries \\
\hline & & Pavement failure & Existing pot holes \\
2 & Road Conditions (IRC:SP027) & Foot paths & None \\
& & Speed breaker & Non-scientific \\
\hline
\end{tabular}


Volume 5, Issue 4, Pages 30-38, Oct-Dec 2021

\begin{tabular}{|c|c|c|c|}
\hline 3 & Type of Collision & Head on & 15 \\
& & Side sweep & 03 \\
\hline 4 & Sign Board & Sign boards and indication & None \\
\hline 5 & Visibility & Day and Night & Good \\
\hline 6 & Bush Clearance & Shreds and other & Exists \\
\hline 7 & Street Light & Halogen or LED & Does not exists \\
\hline
\end{tabular}

The suggestions are listed below:

a) Marking and delineators need to be provided.

b) Mandatory signal and sign board need to be placed.

c) Foot path for pedestrians to be provided.

d) All the pot holes need to be filled.

e) Street lights to be provided.

f) Standard median to be built upon.

From the above analysis the main causes of black spots or accidents depends on design of roads, type of users, vehicle faults, improper sign boards and other environmental factors. The driving conditions such as over speeding and drunken driving may also contribute to it.

\section{Conclusions}

In the study an attempt was made to find out most vulnerable accident spots at a stretch from 8th mile to Heasaraghatta. The Weighted severity index (WSI) method and accident density method was used to rank the accident locations on selected section of State highway-39. The top four spots were selected as black spots as per WSI value from the collected road traffic accident data and suggestions were also provided to improve the transportation system. From the analysis it was observed that, most of the accidents are due to collisions between the vehicles or to the nearby objects. Which is due to bad signage or bad alignment of the road with It is essential to rectify these severe prone zones to reduce the fatalities [7].

\section{Based on the analysis some of the major observation were drawn and are listed below:}

1) The road signs and indications are vital.

2) The road specification must be followed accurately.

3) The consciousness of the drivers is important.

4) Everyone should follow the basic driving guidelines.

5) Proper light facilities and speed breakers need to be provided at specific locations. 


\title{
Acknowledgement
}

The authors thank the Karnataka police department for providing the information to complete the project.

\author{
Declarations \\ Source of Funding \\ This research did not receive any grant from funding agencies in the public, commercial, or not-for-profit sectors. \\ Competing Interests Statement \\ The authors declare no competing financial, professional and personal interests.

\section{Consent for publication} \\ Authors declare that they consented for the publication of this research work.
}

\section{References}

[1] Road Accidents in India, (2019. Ministry of Road Transport and Highways Transport Research Wing, Government of India (GOI).

[2] Rajasekaran, R.B., Rajasekaran, S., \& Vaishya, R., (2021). The role of social advocacy in reducing road traffic accidents in India. Journal of Clinical Orthopaedics and Trauma, 12(1): 2-3.

[3] Khamankar, D.R., Pawade, P.Y., \& Khode, B.V., (2021). Accident Analysis and Blackspot Identification at Chandrapur City. Internation Journal of Scientific Research in Science and Technology, 8(2): 428-439.

[4] Hashimoto, S., Yoshiki, S., Saeki, R., Mimura, Y., Ando, R., Nanba, S., (2016). Development and application of traffic accident density estimation models using kernel density estimation. Journal of traffic and transportation engineering (English edition), 3(3): 262-70.

[5] Balasubramanian, V., Sivasankaran, S.K., (2021). Analysis of factors associated with exceeding lawful speed traffic violations in Indian metropolitan city. Journal of Transportation Safety \& Security, 13(2): 206-22.

[6] Verma, S., \& Khan, J., (2018). Identification and Improvement of Accident Black Spots on N.H.86 District Sagar, Madhya Pradesh. International Research Journal of Engineering and Technology, 225-232.

[7] Damodariya, S.M., \& Patel C.R., (2021). Black Spot Identification for National Highway47: A Case Study of Godhra-Gujarat Mp Border Stretch. Reliability: Theory \& Applications, SI1 (60). 